NASA Technical Memorandum 83591

\title{
Rural Land Mobile Radio Market Assessment and Satellite and Terrestrial System Concepts
}

Steven M. Stevenson and Charles E. Provencher Lewis Research Center Cleveland, Ohio

Prepared for the

Tenth Communications Satellite Systems Conference sponsored by the American Institute of Aeronautics and Astronautics Orlando, Florida, March 18-22, 1984 


\title{
RURAL LAND MOBILE RADIO MARKET ASSESSMENT AND
}

SATELLITE ANO TERRESTRIAL SYSTEM CONCEPTS

\author{
Steven S. Stevenson and Charles E. Provencher \\ National Aeronautics and Space Administration \\ Lewis Research Center \\ Cleveland, Ohio 44135
}

\section{SUMMARY}

For the past several years the Lewis Research Center has been conducting studies concerning land mobile radio with the primary objective of determining the most effective role satellite systems might play in providing this service in the rural United States (outside of the 313 Standard Metropolitan Statistical Areas). This objective has been addressed by: (1) determining if sufficient market potential exists; (2) characterizing the nature of the market in terms of service needs, usage characteristics, service requirements, and forecasting the demand to the year 2000; (3) defining alternative system concepts that show promise in addressing the identified needs, in a cost effective manner; and (4) identifying advanced technology requirements associated with these concepts. This effort was initiated with inhouse scoping studies to develop a basic understanding of these areas and to identify problems and issues requiring more in-depth study. Subsequently, two study contracts were awarded, one to the General Electric Company (GE) and the other to TRW, to conduct more in-depth analyses. This report summarizes and discusses the major findings of these studies.

\section{INTRODUCTION}

The FCC allocation of a portion of the UHF band (806-890 MHz) for mobile telephone service and its subsequent licensing of cellular systems in many major urban areas has spurred a flurry of interest and activity in the mobile industry. Wireline and radio common carriers are quickly moving to implement these new systems to provide vastly greater capacity and service of much higher quality than presently available. Most of the major Standard Metropolitan Statistical Areas (SMSA's) should have this service by the end of the century. This widespread implementation, however, will still leave the rural populus, inhabiting more than 80 percent of the geographic area of the United States, without similar service. Also, although mobile radiotelephone will be the dominant new mobile radio service in urban areas, a need for expanded and improved mobile dispatch and data services is expected to continue outside these areas.

Over the past several years the Lewis Research Center has been conducting studies to examine the possible role of satellites in providing mobile radio communications in rural areas.

The overall objectives of the Lewis Research Center effort have been to:

1. Assess demand for rural mobtle radio communications; 
2. Assess the feasibility of addressing rural mobile radio needs with both terrestrial and space systems;

3. Determine the relative merits of such systems including system economics; and

4. Identify enabling advanced technology requirements of such systems.

Initially, in-house studies were conducted to assess the potential demand, scope preliminary satelilte system concepts, analyze system economics and estimate subscriber charges. The demand estimates and satellite system results were sufficiently promising to warrant in-depth examination through study contracts with major system suppliers. Consequently two study contracts were awarded, one to the General Electric Company (GE) (ref. 1) and the other to TRW. (ref. 2) These studies, although in many ways similar, were conducted entirely independently and with somewhat different goals and objectives. The objectives of the GE study were to:

1. Develop a market model of the future demand for a variety of moblle radio service applications including mobile telephone, dispatch services, various data applications, and other services not necessarily traditionally provided by mobile radio;

2. Construct several alternative terrestrial and space system concepts that address the forecasted future needs for nationwide rural land mobile service:

3. Estimate system costs and subscriber charges for each concept;

4. Compare concepts and analyze tradeoffs to define the most effective role for satellites; and

5. Identify new technology requirements.

Whereas a major part of the GE study was to develop a market model, the TRW study emphasized system concept development. A market forecast was supplied to TRW by the Lewis Research Center based on the earlier in-house effort. Only mobile telephone service was considered, and in some cases the forecasted market differed significantly from the estimates later provided by GE. The objectives of the TRW study were to:

1. Define three space system concepts to serve the estimated market;

2. Examine system economics including subscriber charges;

3. Identify required technology developments; and

4. Provide a development plan for achieving the technologies identified. This report summarizes and discusses the major findings of each study. 


\section{SUMMARY OF GE STUDY}

The first task of this study consisted of defining a market model for rural land mobile radio for the U.S. This model included information on the basic services to be provided, the total aggregate demand forecast to the year 2000, and the geographic distribution of demand. The basic services identified, that would comprise the bulk of mobile radio demand, were found to be the following, segmented into three generic service classes:

1. New services such as long haul trucking (voice, position location, alphanumerics) and remote service for the 011 and gas industry. New services are defined as services that are not now provided but for which there has been a clearly expressed need. There are a long 1ist of examples, but trucking and 011 and gas probably represent the largest demand and are the easiest to quantify:

2. Dispatch services; and

3. Mobile telephone services.

Three types of forecasts, "conservative," "likely," and "optimistic," based on different assumptions, were made. Finally, geographic distributions for all three service categories were constructed. The 011 and gas services were distributed according to current industry activity on a state by state basis. The trucking geographic distribution was determined on the basis of diesel fuel usage per state. The dispatch services distribution was found to be, after much searching, reasonably well correlated, on a local basis, with certain demographic factors such as population, local income, types of local industry, and others. The geographic distribution of dispatch traffic was constructed to the county level for all of the U.S. using Census Bureau data. The distribution is based on present day actual dispatch traffic and not forecast to later years. A first approximation to the future traffic distribution would be to scale the local present traffic by the growth in the overall aggregate dispatch traffic.

The moblle telephone traffic distribution, on the other hand, was taken to be proportional only to geographically local population density. The basis for this relationship came from published data and forecasts by ATaT (ref. 3) Motorola (ref. 4) and others in the industry. The geographic distributions, here, represent the amount of traffic that could potentially exist now for high quality, cellular-like service, not what's really there now. Again, to make future projections, the local demand was scaled according to the overall growth in rural mobile telephone demand.

Table I presents the results of the GE "likely" forecast in terms of numbers of moblle units. Busy hour Erlangs 1 per unit for each type of service is also shown. Table II shows the corresponding total demand in terms

1 An Erlang is a dimensionless measure of traffic intensity (call-minutes/minute); one Erlang represents a traffic path or channel that is continuously occupled. For example, moblle telephone users typically generate about 0.03 Erlangs per unit or about 30 users generate one Erlang. 
of Erlangs. Although dispatch users comprise about three times the mobile telephone users by the year 2000, the Erlang loads generated are about the same since the dispatch usage per user is about one-third that of mobile telephone.

Table III presents the overall demand estimates in Erlangs, for the "conservative," "likely," and "optimistic" forecasts. The "optimistic" forecast for the year 2000 is about 7 times the "conservative" and twice the "likely." The following discussion is based on the "likely" forecast.

Figures 1 and 2 depict the geographic demand distributions for mobile telephone and dispatch services respectively. The superimposed grid is an approximate representation of the beam coverage areas produced by a 100-beam satellite located at $100^{\circ}$ West Longitude. The size of the black squares is proportional to the demand in that area.

Overall, the forecast results indicated that a large market potential exists outside the SMSA's. Consequently, alternative terrestrial and space system concepts to address this demand were formulated by GE and their relative merits compared.

In attempting to address the forecasted demand with terrestrial systems, GE examined four alternative system types that varied in complexity and capability. These varied from a system providing fully cellular compatible, integrated nationwide service to a distribution of single cell systems, completely independent from one another (i.e., no handoff capability), tied only into the local TELCO and providing a reduced grade of service. The four system types are summarized in table IV.

Capital costs and subscriber charges were formulated for each system and are shown in table $v$. Note that although cell site costs do not vary greatly among systems, the subscriber charges vary about 7 to 1 due to complexity, system area coverage, and other factors. Only systems "C" and "D" appear. to have reasonable subscriber charges as compared to present cellular experience. These charges could be lower in many rural areas since GE chose to base them on a minimum acceptable user density of 0.2 per square mile and the average user density could be higher than this.

For the space system concepts, GE developed a parametric range of system capacity, from a single coNUS beam satellite system to a 100-beam satellite system. Altogether, five point designs were developed including a coNUS system, a 12-beam system, a 31-beam system, and two versions of the 100-beam system.

All of the GE space system concepts consisted of a two-satellite system, each satellite oppositely polarized (circular polarization) with $10 \mathrm{MHz}$ bandwidth, a network operations center (NOC) and a spacecraft operations center (SOC), for network and spacecraft control. The satellites interact directly with mobile units in the field, and interact with the terrestrial fixed network via a multitude of low cost gateway stations located at TELCO switching centers and dispatch users premises. The mobile links are, of course, at UHF while the fixed links were assumed to be at $S$-band, at least up to the 31 -beam class spacecraf.t. Beyond this, multiple S-band beams must be 
used for the fixed links because of needed additional bandwidth. Alternatively, Ku-band fixed links were examined for the larger size spacecraft and these were found to result in overall lower costs because of no fixed link multiple beam requirement. The GE space system concept is shown in figure 3 , and the parametric range of spacecraft configurations is described in table $V I$.

This range of space system configurations resulted in a space system capability model which was superimposed on the forecasted market model to match the appropriate systems with the market demand. The space segment was assumed to have a seven-year lifetime and a two-generation system was postulated, the first becoming operational in 1987, the second in 1994 and ending at the end of the year 2000. A system of slightly greater capability than the 31 -beam system was found suitable for the first generation system. The second generation system that matches the likely market in the year 2000 is a little over twice this size ( 71 beams) and has a space system investment cost of 1.45 billion dollars.

The system investment costs were formulated as a function of system capacity in terms of $4 \mathrm{kHz}$ circuits. $4 \mathrm{kHz}$ bandwidth was assumed to be sufficient for amplitude companded single sideband voice channel operation, while FM volce could be accommodated by 15 or $30 \mathrm{kHz}$. The space segment investment cost, in 1982 dollars, is shown as a function of number of $4 \mathrm{kHz}$ circuits per two-satellite system in Figure 4. Note that the GE results indicate a lack of economy of scale as system sizes are increased beyond about the system "C" concept size. This is due to the increasing weight and power requirements of the fixed link. Beyond this point, multiple beams are required for the fixed link at S-band, with attendant on-board switching, or if Ku-band is introduced as the fixed link, higher power levels are required to maintain link avallability.

Three versions of each configuration are 111 ustrated by the curves of figure 4. The two upper curves represent spacecraft radiated powers of $+5 \mathrm{~dB}$ and $+10 \mathrm{~dB}$ above the nominal designs. This range was chosen to match the uncertainty in available mobile vehicle antenna gains and to determine the consequent impact on spacecraft design and cost. This also accounts for the ranges in spacecraft power, weight and cost shown in table VI.

The investment costs were then transformed into equivalent annual circult costs. GE employed a modified net present value process, treating the space segment investment as a "lump sum" initial payout, discounting at two different values of return on investment, 20 and 40 percent, assuming revenues proportional to the exponential growth in demand, and a payback scheme proportional to the revenue income. This process resulted in a subscriber monthly charge for each type of service provided by the system.

As noted earlier, the space system interacts with the terrestrial system via low cost "gateways"-earth terminals situated at TELCO local loop offices and dispatch users' headquarters. In this way, long distance charges are avoided. It should be noted, however, that significant increases in mobile subscriber charge would be incurred if toll interconnects are required between the fixed telephone network and gateway stations. Table VII presents some of the subscriber charge results for the second generation system. FM mobile telephone voice service at $\$ 168$ per month $(15 \mathrm{kHz}$ voice) is comparable to 
expected cellular charges, but cellular compatible $30 \mathrm{kHz}$ voice would cost considerably more (about $\$ 300 \mathrm{per}$.month). The $15 \mathrm{kHz}$ voice monthly charge is composed of $\$ 128$ for the space segment, $\$ 14$ for the gateway, and $\$ 26$ for the mobile unit.

\section{GE CONCLUSIONS}

GE generally concludes the following from their results:

- Space systems for rural mobile radio service are superior to terrestrial systems

-..they can provide ubiquitous, high quality service

--a nationwide architecture is easily provided; a moblle unit can call to or be reached from anywhere in the country

- -mobile units including antennas for operation with satellite systems are not significantly more costly than present cellular mobile units

- Satellite subscriber charges are lower than those of terrestrial systems. providing equivalent service

-. $15 \mathrm{kHz}$ voice (mobile telephone) is comparable to today's cellular price

- $30 \mathrm{kHz}$ cellular compatible voice is probably too expensive except for occasional use, e.g., a cellular subscriber roaming outside his home system

-all dispatch type services are provided at $4 \mathrm{kHz}$ channel bandwidth as a way of minimizing the space segment cost

--acceptable subscriber charges are possible through a national network of gateway stations co-located with TELCO local offices and large users' premises; long haul terrestrial links are minimized

- Terrestrial systems servicing the non-SMSA population can be compatible with urban cellular systems but have limitations:

--the $800 \mathrm{MHz}$ band is not well suited for conventional, large area coverage terrestrial service; it has a short-range, is easily blocked, generally provides very "spotty" service

--there is no economically practical way to implement a national architecture; calls of any distance would incur long distance charges. Service would be like present Improved Mobile Telephone Service (IMTS), only at $800 \mathrm{MHz}$

--terrestrial systems can not well serve new services like oil and gas, trucking, data collection, many public services, and others because of their general requirement of ubiquitous availability of service

- - only user densities greater than 0.2 subscribers per square mile could be economically served (about 80 percent of the non-SMSA population and 
about 50 percent of the geographic area)

- -service quality standards would have to be severely relaxed from cellular standards to achleve costs comparable to cellular

\section{SUMMARY OF TRW STUDY}

This study examined operational land mobile satellite systems for radio telephone service in the 1990's time frame, identified critical technologies, and structured a technology development program. The system portion of the study examined three satellite system concepts which are illustrated in figure 5 .

\section{System Concept 1 - Direct to Mobile}

In System Concept 1, the mobile unit communicates with the satellite directly. Ten system configurations were first examined (table 8 ) in a toplevel fashion to cover a range of the important variables affecting system design. For each of the ten cases in table VIII, a baseline traffic scenario with an assumed uniform traffic distribution was used and monthly subscriber charges were computed to evaluate the 10 cases. Two cases ( 7 and 10) were subsequently selected for a more detailed examination. This included determining satellite weights and powers at the subsystem level and a more detailed analysis of the satellite antennas. In addition, these two selected cases were examined for a number of alternative traffic scenarios in addition to the baseline (fig. 6) in order to explore system design sensitivity to uncertainties in market estimates.

As indicated in table VIII, both single and multiple spacecraft cases were examined. A single spacecraft permits the use of a relatively simple, omni-type, mobile antenna. TRW assumed a drooping dipole with a maximum gain of $3 \mathrm{dBi}$. On the other hand, a low gain mobile antenna requires a high EIRP on the satellite. Multiple spacecraft (which ultimately proved to be the better solution) requires a mobile antenna with sufficient directivity to be able to discriminate one satellite from the others. Also, because of this directivity, the mobile antenna must be a tracking-type antenna to accommodate vehicle motion. For this antenna, TRW designed a mechanically steered, four-element microstrip array antenna (figs. 8 and 9 ) with a maximum gain of $9 \mathrm{dBi}$.

Multiple satellites proved to be a better approach than a single satellite because of two factors; traffic skew and a constraint, for the purposes of this study, on the size of a single satelitite. The latter required that the satellite not weigh more than 10000 pounds nor require more than a single shuttle launch.

The impact of traffic skew on the satellite size can be understood by considering a single satellite located at $100^{\circ} \mathrm{W}$ longitude. A beam on Northeast CONUS will cover about twice the area that a beam on South Central conUS will cover due to the difference in the way in which equal sized beams project onto the surface of the earth. Also consider that the population density in Northeast CONUS is much greater than it is in South Central CONUS. Therefore, the actual number of users in the Northeast beams will be much greater than those in the South Central beams. As a result, the Northeast beams will saturate while the South Central (and other) beams will be 
underutilized. TRW found, for example, that in the case of the baseline traffic scenario (180 000 users) only 120000 users could be served (about two-thirds) when the Northeast beams were saturated. Thus, in order that the satellite can serve the full 180000 users, it would have to be designed for a greater total capacity (in essence, overdesigned). This would result in a satellite considerably in excess of 10000 pounds, the prescribed design constraint. Multiple satellites, on the other hand, which can share the traffic load, can each be designed within the 10000 pound constraint.

An important parameter in the study of the ten configurations for system 1 was UHF bandwidth allocation. TRW was directed to examine three allocations as indicated in table VIII; 4, 10, and $20 \mathrm{MHz}$. These allocations are as follows:

\begin{tabular}{rlll} 
Allocation & \multicolumn{1}{c}{ Uplink } & Downlink \\
\cline { 2 - 3 } $4 \mathrm{MHz}$ & $821-825 \mathrm{MHz}$ & $866-870 \mathrm{MHz}$ \\
$10 \mathrm{MHz}$ & $821-831 \mathrm{MHz}$ & $866-876 \mathrm{MHz}$ \\
$20 \mathrm{MHz}$ & $825-845 \mathrm{MHz}$ & $870-890 \mathrm{MHz}$
\end{tabular}

The $4 \mathrm{MHz}$ bands are currently allocated by the FCC as reserve bands, and NASA has petitioned the FCC to permit mobile satellite operations in these bands. A rulemaking on this petition is still pending. The $10 \mathrm{MHz}$ bands would require a rearrangement of the current reserve bands (82)-825 MHz, 845-851 $\mathrm{MHz}, 866-870 \mathrm{MHz}$, and 890-896 MHz) into two, $10 \mathrm{MHz}$ segments allocated for mobile satellite use. This would also require a $6 \mathrm{MHz}$ upward shift of the $20 \mathrm{MHz}$ bands currently allocated for cellular mobile systems. This was thought to be a possibility at the start of the studies, but is now considered to be highly unlikely. To get even more bandwidth for mobile satellite systems, the $20 \mathrm{MHz}$ bands currently allocated to cellular mobile systems were examined for the possibility of sharing these bands between urban cellular and rural satellite systems. This proved to be not feasible primarily because of excessive interference of the cellular system mobiles with the mobiles attempting to communicate through the satellite, i.e., interference into the uplinks to the satelilite.

Because the bandwidth that might be allocated for moblle satellite communications in the 806-890 MHz band is so limited, high frequency reuse is required in order to serve the potential market. This leads to the need for multiple, spot beam antennas. Because the frequency is relatively low, very large antennas, such as those indicated in table VIII, are required. These antennas significantly influence the size and cost of the spacecraft.

TRW examined a number of different antenna designs. Three different structural design approaches were examined. These included:

1. Wrapped Rib

2. Hoop-Column

3. Box-Truss

of these, the wrapped $\mathrm{rib}$ and hoop-column design approaches appeared to have a weight advantage over the box-truss approach. 
Optical design approaches examined included center fed and offset fed designs. For the latter, direct offset fed as well as offset fed Cassagrain designs were investigated. The Cassagrain design approach resulted in a heavier antenna than the direct offset fed approach and was not considered in any detall.

The center fed and direct offset fed design approaches were examined in detall using Case 7 (table VIII). They were both designed to the same traffic and were required to meet the same performance levels.

The direct offset fed design was able to meet the performance criteria using only four frequency subbands and a beam pattern that required the center-to-center distance between beams of like frequencies to be two beamwidths. The resulting antenna required 61 beams, was $46 \mathrm{~m}$ in diameter and weighed 3,420 pounds.

The center fed design, while structurally simpler than the direct offset fed design, produced higher sidelobe levels because of blockage by the mast and feed array. Consequently, to meet the same performance criteria as the direct of fset fed design, the center fed design required seven frequency subbands and a center-to-center spacing of beams of like frequency of 2.65 beamwidths. The resulting antenna required 101 beams, was $62 \mathrm{~m}$ in diameter and weighed 2,940 pounds.

Another important aspect examined in the TRW study was the degree to which mobile telephone service via satellite would or could be compatible with planned terrestrial cellular systems. For this reason, the study initially examined the use of narrowband FM with 2:1 companding and $30 \mathrm{kHz}$ channel spacing, typical of cellular mobile phone systems being planned.

As it turned out, maintaining compatibility with cellular systems would not be an efficient use of avaliable spectrum and limits the number of subscribers that could be served. In order to handle the assumed traffic loads in the most cost effective manner possible, alternative schemes for reducing channel spacing were considered. One modulation scheme for which the technology is available and which appeared cost effective while still providing toll quality voice service, was a narrowband FM system with $12 \mathrm{kHz}$ channel spacing and a peak deviation of $5 \mathrm{kHz}$. During the study, Motorola, under subcontract to TRW, established noise figures and interference levels to be used in the study for such a system. This modulation scheme was used in Cases 5-10 (table VIII).

All system concepts studied are designed to permit the user to access commercial switched telephone networks. This is accomplished through gateway terminals which have a two-way link with the satellite, and which process RF signals from the satellite into a form suitable for entry into the telephone network or, conversely, convert signals from the telephone network into a satellite link-compatible signal. Depending on the size of the system, 8 to 12 gateways are used. This applies to all the system concepts. For system 1 , the link between the gateway and the satellite was assumed to be at Ku-band and a multibeam spacecraft antenna was used to produce a spot beam for each gateway. TRW assumed that each gateway beam would be cross-strapped to 7 UHF beams on the satellite. Simple frequency translation and multiplexing of the $10 \mathrm{MHz}$ bandwidth from each of $7 \mathrm{UHF}$ beams lead to a gateway beam bandwidth of $100 \mathrm{MHz}$ including guard bands. The use of separate, noncontiguous spot beams 
for each gateway permits the same $100 \mathrm{MHz}$ to be used for each gateway, thereby avoiding excessive use of the Ku-band.

As system configurations were defined, their costs were then estimated. The space segment costs, the terrestrial segment costs, and the cost of doing business, such as cost of money and taxes, were included. The total system cost and the number and capture rate of users became the input to a net present value program which calculated the monthly service charge to a user for different rates of return. The monthly service charge was used as a basis for comparing systems. Of the ten System 1 cases studied (table VIII), Case 7 appeared most attractive. The monthly user service charge for this case is shown in figure 7 as the "direct to mobile" curve. Traffic scenario B (fig. 6) was used which has 350000 users at the end of 7 years. Also, the satellites for this case were assumed to use a direct offset fed antenna.

\section{System Concept 2 - Mobile Translator}

The second system concept incorporates a terrestrial network of earth terminals called translators because they convert the UHF signal from the mobile unit to $\mathrm{C}$ - or $\mathrm{Ku}$-band for the earth to satellite link. It is possible to use the $\mathrm{C}$ - or $\mathrm{Ku}$-band frequencies because the translator stations are large, permanent facilities that can be designed to meet FCC requirements for ground terminals in the fixed satellite service. Using the allocations for fixed satellite service eliminates the need for a dedicated satellite, as transponders can be leased on a commercial communications satellite. TRW assumed the use of leased transponders as a means of reducing the cost of the space segment. Therefore, the main capital investment in system concept 2 became the cost of the translator stations. About 400 of these are required to cover 50 percent of coNUS using the TRW assumption that a transmission range of 40 miles is achievable when the station has a 500 foot tower and an ERP of $21 \mathrm{dBW}$. In order for the mobile unit to transmit to the translator, the mobile unit ERP must be 3 watts.

The other capital investment item in System Concept 2 is the gateways. However, only 12 gateways are required, and their total cost is only a fraction of the total cost of the translator stations. Combining the total terrestrial capital investment, the cost of doing business, the cost of the leased transponders, and the number of subscribers, a monthly service charge per user was calculated. The curve in figure 7 labeled "mobile to translator" shows the monthly service charge versus the rate of return. Here again, traffic scenario $B$ is used.

\section{System Concept 3 - Hybrid}

The third system concept retains all the features of the second concept plus the addition of direct UHF links from the satelite to remote mobile units called transportables. For this system concept, the satellite must transmit at UHF as well as at $C$-band, and since commercial $C$-band communications satellites do not include UHF transponders, a leased satellite is not possible. A dedicated satellite is required, and in order to simplify the satellite and minimize its cost, the satellite was designed to produce a conUS coverage C-band beam for the translator terminals, and a UHF CONUS beam for the transportables. The transportable unit antenna was required to have a gain of $15 \mathrm{dBi}$. TRW selected a helical antenna about 1 meter in length. This 
antenna can only be deployed when the mobile unit is stationary, hence the name transportable.

For this system concept, a UHF frequency allocation of $4 \mathrm{MHz}$ was assumed. Also, in anticipation that the transportable units would transmit data, a $30 \mathrm{kHz}$ channel spacing was used. With these restrictions, only about 4,600 transportables could be served. However, the spacecraft power and antenna required for the UHF link to the transportables became the spacecraft cost drivers.

TRW calculated the monthly service charge for System Concept 3 based on voice traffic only. Two approaches were used. One has mobiles and transportables each charged in proportion to their share of the system cost. With this approach, the mobile unit subscriber would pay the same charge that occurs in System Concept 2, but the transportable user would pay a monthly service charge that is 30 times greater. This results from having only 4,600 transportable users paying for the UHF space segment. The second approach has mobile users and transportable users pay a common service charge which, in effect, has the mobile users subsidizing the transportable users. A curve of the subscriber monthly service charge versus rate of return is shown on figure 7 for this second approach (labeled "hybrid system"). It should be noted that with this approach to charging for service, the mobile unit user would pay a slightly greater monthly service charge than in the first approach, and the transportable user would pay the same charge as the mobile unit user instead of 30 times as much.

\section{TRW SYSTEM STUDY CONCLUSIONS}

\section{Relative to System Concept 1, TRW concluded the following:}

1. It is not feasible for land mobile satellite systems to share the 20 $\mathrm{MHz}$ bandwidth currently allocated to cellular mobile systems.

2. For the assumed baseline traffic scenario, $4 \mathrm{MHz}$ of bandwidth (current allocated reserve bands) appears inadequate to meet the traffic without requiring at least 4 satellites to achieve sufficient frequency reuse. This would require a directivity in the mobile antenna which may not be practically achievable.

3. A $10 \mathrm{MHz}$ bandwidth permits feasible satellite system designs (2 to 3 satellites). In order to achieve a user antenna of a practical size for mobile vehicle applications able to discriminate between satellites, it was found that the satellites would have to be spaced at least $30^{\circ}$ apart in orbit. Coupled with the need to maintain a minimum elevation angle of $10^{\circ}$ from the mobile unit to a satellite, the number of satellites serving conUS cannot exceed three.

4. With a $10 \mathrm{MHz}$ bandwidth it was found that multiple satellites would also be required in order that each satellite would meet the 10,000 pound weight constraint.

5. It was found that the subscriber charge for the best "directto-mobile" telephone system would not be competitive with estimated cellular mobile telephone charges. 
Relative to System Concept 2, TRW concluded that based on the assumption used, this system concept, which includes using a leased, fixed service satellite, is the most cost effective of the three concepts studied. Subscriber charges appear to be competitive with estimated cellular mobile telephone. charges.

Relative to System Concept 3 , the need to serve transportable terminals at UHF required a dedicated satellite having CONUS coverage beams, one at C-band and the other at UHF. The use of a CONUS coverage beam at UHF would require a transportable antenna having a minimum gain of $15 \mathrm{dBi}$. Because this system concept requires a dedicated satellite with its associated in-orbit spare and ground spare, the space segment cost would be relatively high. Thus, the subscriber charges for this system would be comparable to system concept 1.

\section{TECHNOLOGY ISSUES}

GE and TRW both identified technology issues which they concluded were. necessary to resolve in order to successfully implement a land mobile satellite system. A compllation of their recommendations is shown in figure 10 . Note that both contractors agree on the large UHF satellite antenna as a requirement, but their view of the technology issues was different. GE was concerned with achieving a successful mechanical design; one which could be , deployed in a low earth orbit for an in-orbit checkout, and retrieved and.. restowed in the shuttle payload bay for return to earth if the checkout revealed a problem that needed to be eliminated. TRW anticipated that a successful mechanical design would be achieved, but expressed concerns about the dynamics problems and in-orbit control of such a large spacecraft, in particular, the antenna surface. TRW believes that development of computer programs to simulate the dynamics of these large structures is a necessary prerequisite to designing in-orbit control systems for them.

Upper stages for the STS were also of concern to both contractors. GE expressed the belief that a capability of transporting more than 10,000 pounds from LEO to GEO will be required. TRW's main concern was having the ability to transfer a satellite from LEO to GEO at low thrust. This would permit the deployment of the large antenna in LEO for checkout prior to transfer to GEO.

Concerning UHF amplifiers, GE considers improvements in linearity and efficiency as necessary. GE stated that an efficiency greater than 35 percent should be the goal. TRW considers the technology of solid state amplifiers as mature and does not expect further significant improvements. TRW did not recommend that any specific development effort be implemented. Both contractors indicated that the natural evolution in the state-of-the-art will be sufficient to achieve the desired performance.

Both contractors see the mobile unit antenna as requiring a development program. The antenna must have sufficient gain and directivity to distinguish between two or more satelitites, and yet be of a size and configuration that is acceptable for installation on the roof of a passenger vehicle.

The gateway stations were a technology issue only to GE, and mainly for the necessity to achieve a design amenable to high production fabrication techniques. GE's system utilizes large numbers of gateway stations, and. 
hence, the cost must be kept low by efficient production techniques.

Another technology concern expressed by GE was that of the mobile unit transceiver itself. They expressed the need for a development program to adapt the existing mobile transceiver design for satellite service. TRW expressed the need for such design changes but stated that this was an engineering design problem within the current state-of-the-art.

\section{CONCLUOING REMARKS}

The study results indicate that sufficient rural market potential exists for consideration of large scale mobile radio systems and that both space and terrestrial system concepts addressing this demand show potential economic feasibility. Space systems exhibit much greater flexibility in implementing a national system architecture, providing ubiquitous nationwide service, and reaching nontraditional users such as 011 and gas industry users and the trucking industry. Terrestrial systems can, however, adequately address much of the rural market for moblle telephone and dispatch services if they are well. tallored to the user geographic distributions, and disregard requirements for ubiquitous U.S. service. Implementation of a national architecture with terrestrial systems appears to be less straightforward, although that's not to say it can't be done. The $800 \mathrm{MHz}$ band is not the most suitable for terrestrial rural mobile systems, but these systems would be compatible with $30 \mathrm{kHz}$ voice channel urban cellular systems. Space systems, on the other hand, have a high cost sensitivity to channel bandwidth requirements. Significant savings in required subscriber charge can be made as voice channel bandwidth is reduced. This, however, sacrifices compatibility with urban cellular systems. Factors needing further exploration in this regard include amplitude companded single sideband techniques allowing voice channel bandwidths on the order of $4 \mathrm{kHz}$, linear predictive coding of voice traffic, and possible use of other frequency bands such as L-band.

Although TRW's Syslem Concept 2 (mobile to transiator system) was found to be the most cost effective of the three concepts they studied, the results are highly dependent on a number of assumptions. Primary among these was the assumption of a 40 mile range for the translator stations. In addition. TRW assumed that the entire traffic for any scenario existed within the 50 to 70 percent of conUS covered by this system. A more detailed investigation of this system concept is warranted to verify these results.

Both contractors see the main new technology requirement to be in the area of large antennas and associated attitude control requirements. Upper stage capabilities greater than currently avallable will be needed. Required improvements in linearized solid state UHF amplifier technology are seen as coming about through natural evolution of state-of-the-art. Fundamentally different means of interconnecting the fixed users with the moblles were conceptualized, and mobile units and vehicle antennas were deemed to pose no particular development difficulties.

\section{RFFERENCES}

1. Anderson, R. E., "Moblle Radio Alternative Systems Study, Executive Summary," General Electric Co., Schenectady, N.Y., 83SRD038, (NASA CR-168207); "Satel11te/Terrestrial (Hybrid) Systems Concepts," GEC-CRD-83-SRD-039, (NASA CR-168064); "lerrestrial Syslems Concepts-Rural Areas," GEC-CRD-83-SRD-038, (NASA CR-168063); "Traffic Mode1," GE-CRD-83-SRD-037, (NASA CR-168062), June, 1983. 
2. Horstein, M., "Requirements for a Mobile Communications Satellite System, Vo1, I: Executive Summary," NASA CR-168128; "Vol. II: Technical Report," NASA CR-168129, 1983.

3. "An Inquiry into the Use of the Bands $825-845 \mathrm{MHz}$ and $870-890 \mathrm{MHz}$ for Cellular Communications Systems..." AT\&T filing before the Federal Communications Commission, CC Docket No. 79-318, August 1980.

4. "An Inquiry into the Use of the Bands $825-845 \mathrm{MHz}$ and $870-890 \mathrm{MHz}$ for Cellular Communications Systems.." Motorola filing, loc cit.

TABLE I. - GE ESTIMATES OF RURAL MOBILE UNITS IN SERVICE,

"LIKELY" MARKET

\begin{tabular}{|l|r|r|r|c|}
\hline \multicolumn{1}{|c|}{ Service } & 1990 & 1995 & 2000 & Erlangs/unit \\
\hline $\begin{array}{l}\text { 011 and gas } \\
\text { Voice }\end{array}$ & 36000 & 41000 & 49000 & 0.01 \\
$\quad$ Data & 7300 & 8400 & 10000 & .007 \\
$\begin{array}{l}\text { Trucking } \\
\text { Tractor } \\
\text { Trailer }\end{array}$ & 87000 & 96000 & 106000 & .01 \\
Dispatch & 168000 & 186000 & 205000 & .00006 \\
Mobile telephone & 217000 & 304000 & 427000 & .028 \\
\hline
\end{tabular}


TABLE II. - FORCASt OF ERLANG DEMAND, "LIKELY CASE"

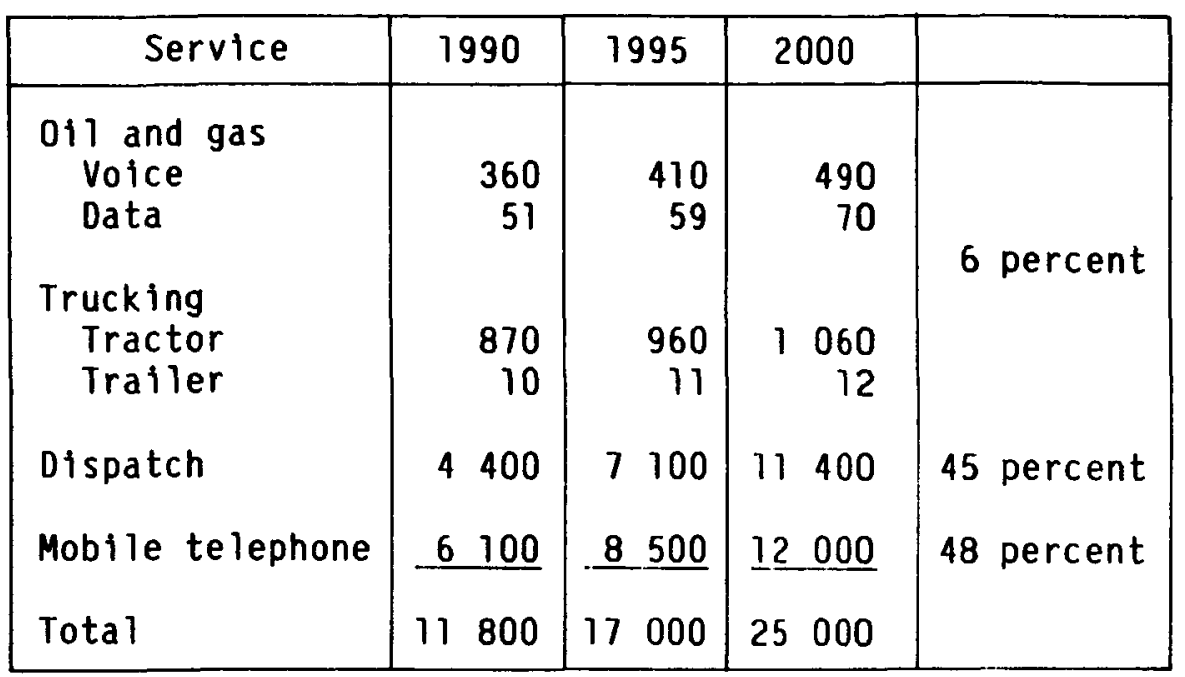

TABLE III. - SUMMARY OF OVERALL DEMAND

ESTIMATES, ERLANGS

\begin{tabular}{|l|r|r|r|}
\hline & 1990 & 1995 & 2000 \\
\hline Conservative & 3700 & 4800 & 5900 \\
Likely & 11800 & 17000 & 25000 \\
Optimistic & 18000 & 29000 & 43000 \\
\hline
\end{tabular}


TABLE IV. - TERRESTRIAL SYSTEMS EXAMINED FOUR TYPES OF SYSTEMS

\begin{tabular}{|c|l|}
\hline System & \multicolumn{1}{|c|}{ Description } \\
\hline A & $\begin{array}{l}\text { Cellular specs's, 6-mile radius cells, 150' base towers, ubiquitous } \\
\text { service. } \\
\text { Reduced grade of service, MTS0 removed, no cell-to-cell hand-off or } \\
\text { vehicle location capabilities exist; service like present IMTS } \\
\text { except at } 800 \mathrm{MHz} 6 \text {-mile cell radius. } \\
500 \text {-foot towers with increased ERP, 15-mile range, remote receivers } \\
\text { (repeaters), serves both vehicles and hand-held portables. } \\
\text { Similar to (c), except no remote receivers, 35 watt HPA added to } \\
\text { vehicle mobile unit, no portables. }\end{array}$ \\
D
\end{tabular}

TABLE V. - TERRESTRIAL SYSTEM COSTS

\begin{tabular}{|c|c|c|c|c|}
\hline System & $\begin{array}{c}\text { Cost/ } \\
\text { cell site, } \\
\text { K }\end{array}$ & $\begin{array}{c}\text { Number } \\
\text { systems in } \\
\text { rural areas }\end{array}$ & $\begin{array}{c}\text { Total capital } \\
\text { cost }\end{array}$ & $\begin{array}{c}\text { Cell site } \\
\text { charge per } \\
\text { subscriber } \\
\$ / \text { Mo. }\end{array}$ \\
\hline A & 393 & 33130 & $\$ 13.0 \mathrm{~B}$ & 718 \\
B & 292 & 33130 & $9.7 \mathrm{~B}$ & 502 \\
C & 377 & 5300 & $2.0 \mathrm{~B}$ & 142 \\
D & 307 & 5300 & $1.63 \mathrm{~B}$ & 106 \\
\hline
\end{tabular}

a Based on user density of $0.2 / \mathrm{sq}$ mile ( 82 percent of rural market has density $\geq 0.2 / \mathrm{sq}$ mile).

- -Most of remaining 18 percent could be served by judiciously co-locating systems with user concentrations and not necessarily covering conus. 
TABLE VI. - SUMMARY OF GE SPACE SYSTEM CONFIGURATIONS

[ $10 \mathrm{MHz}$ allocation (10 up and 10 down); uniform power density for FM and ACSSB; 2 active satellites, 1 ground spare.]

\begin{tabular}{|c|c|c|c|c|c|}
\hline Configuration & A & B & C & $D^{e}$ & $D^{\prime}$ \\
\hline $\begin{array}{l}\text { Number of UHF beams } \\
\text { UHF beamwidtha } \\
\text { Number of fixed } \\
\text { service beams } \\
\text { On-board switching } \\
\text { System capacityb (MHz) } \\
\text { (dual polarization) } \\
\text { Equivalent FM/SSB } \\
\text { circuitsc } \\
\text { Power } \\
\text { Weight } \\
\text { Space system } \\
\text { Invest. (\$M)d }\end{array}$ & $\begin{array}{l}1 \\
6^{\circ} \times 4^{\circ} \\
1 \\
\text { No } \\
20 \\
1333 / \\
5000 \\
767-5700 \\
600-2000 \\
229-393\end{array}$ & $\begin{array}{l}12 \\
1.5^{\circ} \\
1 \\
\text { No } \\
60 \\
4000 / \\
15000 \\
540-1060 \\
1800-2100 \\
465-502\end{array}$ & $\begin{array}{l}1 \\
\text { No } \\
155 \\
10333 / \\
38750 \\
690-1800 \\
3400-3800 \\
759-797\end{array}$ & $\begin{array}{l}100 \\
0.41^{\circ} \\
14 \\
\text { Yes } \\
500 \\
33333 / \\
125000 \\
9000-9800 \\
16600-17000 \\
2200-2210\end{array}$ & $\begin{array}{l}1 \\
\text { No } \\
500 \\
33 \quad 333 / \\
125000 \\
2600-3400 \\
12300-12500 \\
1876-1894\end{array}$ \\
\hline
\end{tabular}

asegmentation 4.1 .

b2 Satellites.

CCFM is $15 \mathrm{kHz}$, CSSB is $4 \mathrm{kHz}$.

dBased on EIRP variations.

eku-band fixed link, all other configurations are S-band.

TABLE VII. - TYPICAL TOTAL SUBSCRIBER CHARGES

(SPACE SEGMEN1, GATEWAY AND MOBILE RADIO)

RATE OF RETURN $=20$ PERCENT

\begin{tabular}{|c|c|c|}
\hline $\begin{array}{c}\text { Trunk type, } \\
\mathrm{kHz}\end{array}$ & Service & $\begin{array}{c}\text { Monthly charge, } \\
\text { dollars }\end{array}$ \\
\hline 4 & Dispatch & 34 \\
4 & Radio telephone & 69 \\
15 & Radio telephone & $\mathrm{a} 168$ \\
30 & Radio telephone & 323 \\
\hline
\end{tabular}

aFor example, Mobile unit + gateway + space segment $=26+14+128=168$. 
TABLE VIII. - SYSTEM I CONFIGURATIONS

\begin{tabular}{|c|c|c|c|c|}
\hline Case & $\begin{array}{c}\text { Channe } \\
\text { spacing, } \\
\mathrm{kHz}\end{array}$ & $\begin{array}{c}\text { Number of } \\
\text { S/C }\end{array}$ & $\begin{array}{c}\text { S/C antenna } \\
\text { diameter, } \\
M\end{array}$ & $\begin{array}{c}\text { Frequency } \\
\text { allocation, } \\
\text { MHz }\end{array}$ \\
\hline 1 & 30 & 1 & 52 & 10 Exclusive \\
2 & 30 & 1 & 4 Exclusive \\
3 & 30 & $3 / 2$ & $30 / 37$ & 10 Exclusive \\
4 & 30 & 3 & 49 & 4 Exclusive \\
5 & 12 & 1 & 31 & 10 Exclusive \\
6 & 12 & 1 & 51 & 4 Exclusive \\
7 & 12 & 2 & 22 & 10 Exclusive \\
8 & 12 & 2 & 36 & 4 Exclusive \\
9 & 12 & 1 & 35 & 20 Shared \\
10 & 12 & 2 & 24 & 20 Shared \\
\hline
\end{tabular}



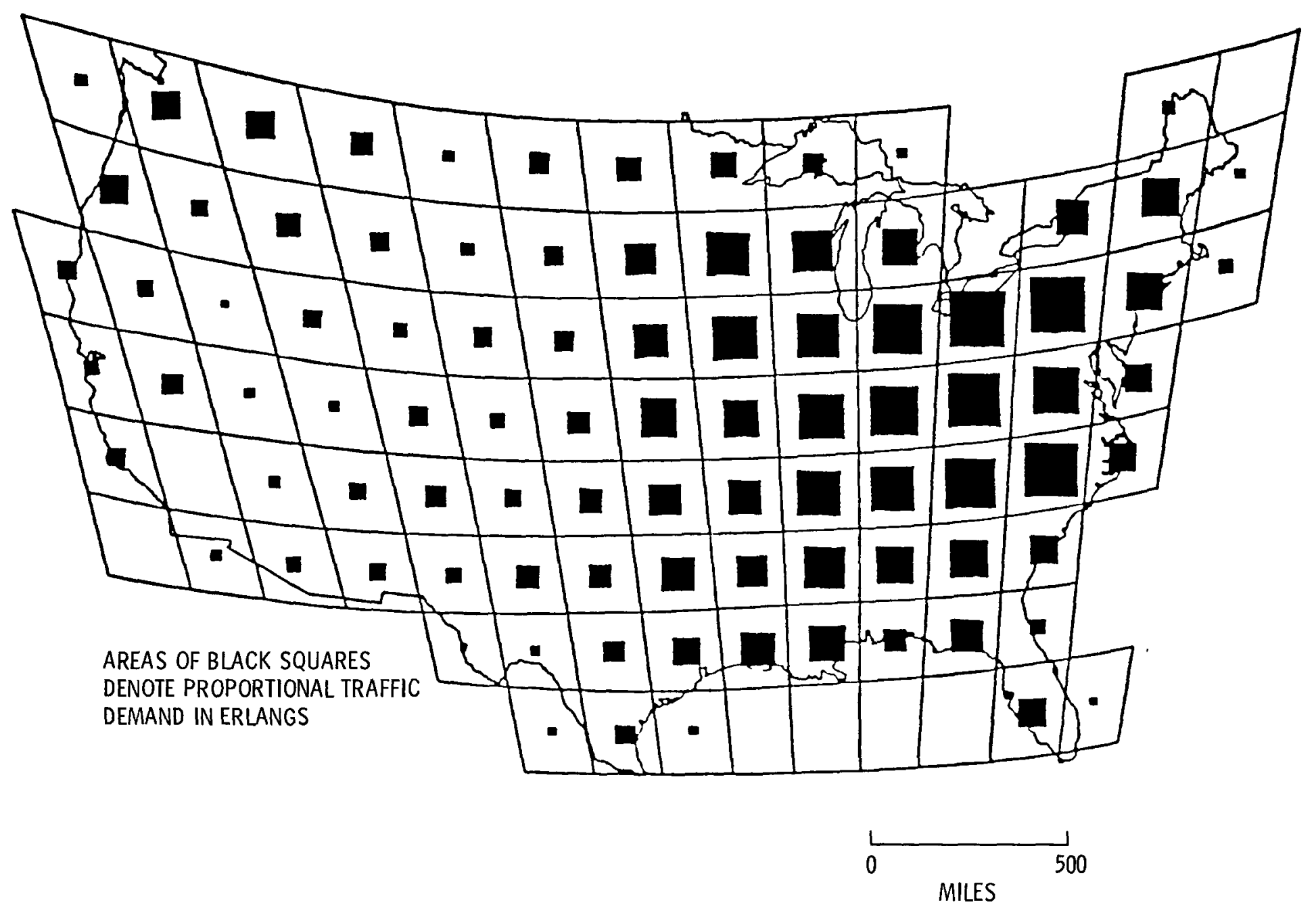

Fig. 1 Demand distribution cellular compatible mobile telephone non-SMSA counties. 


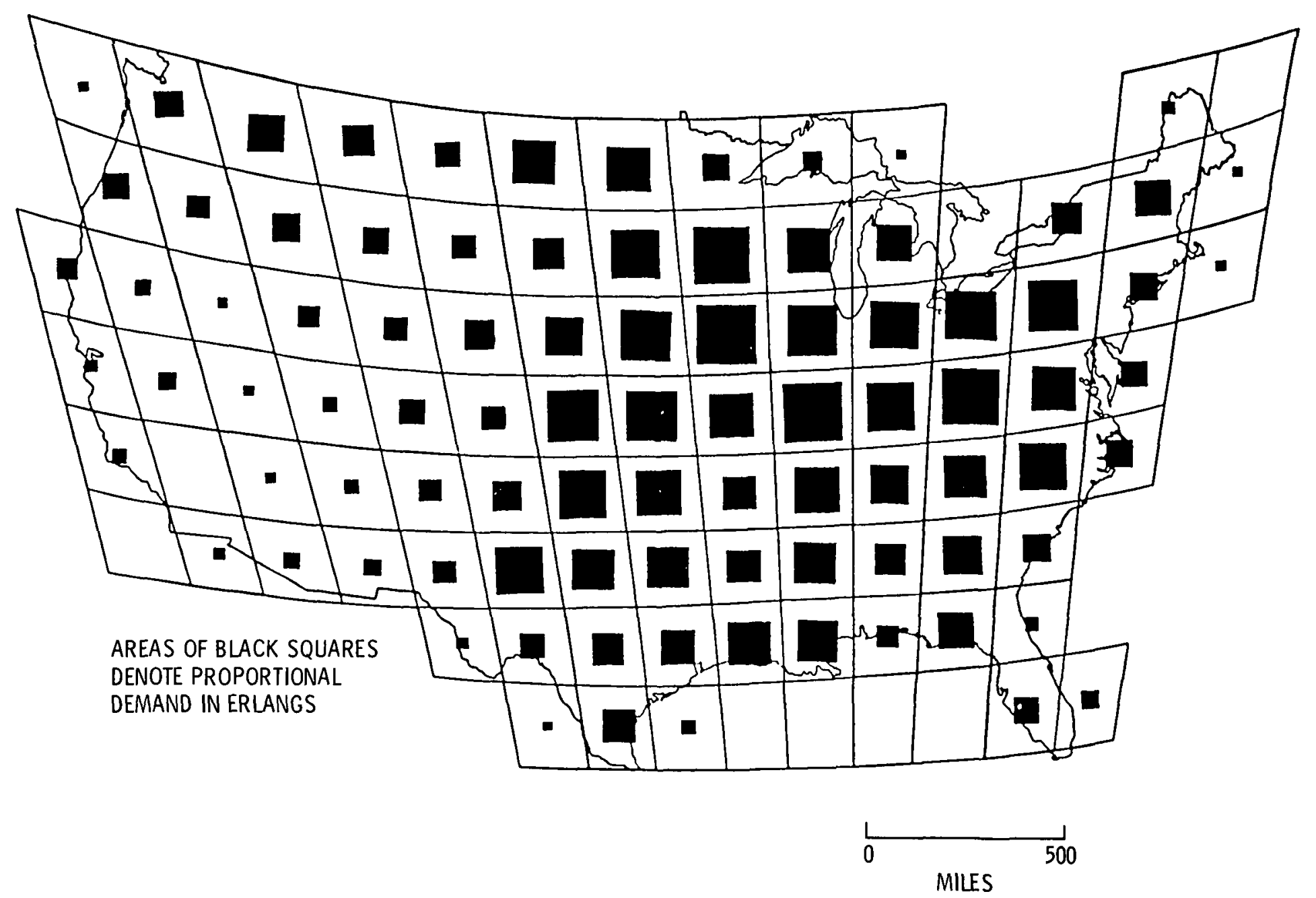

Fig. 2 Demand distribution dispatch radio non-SMSA counties. 


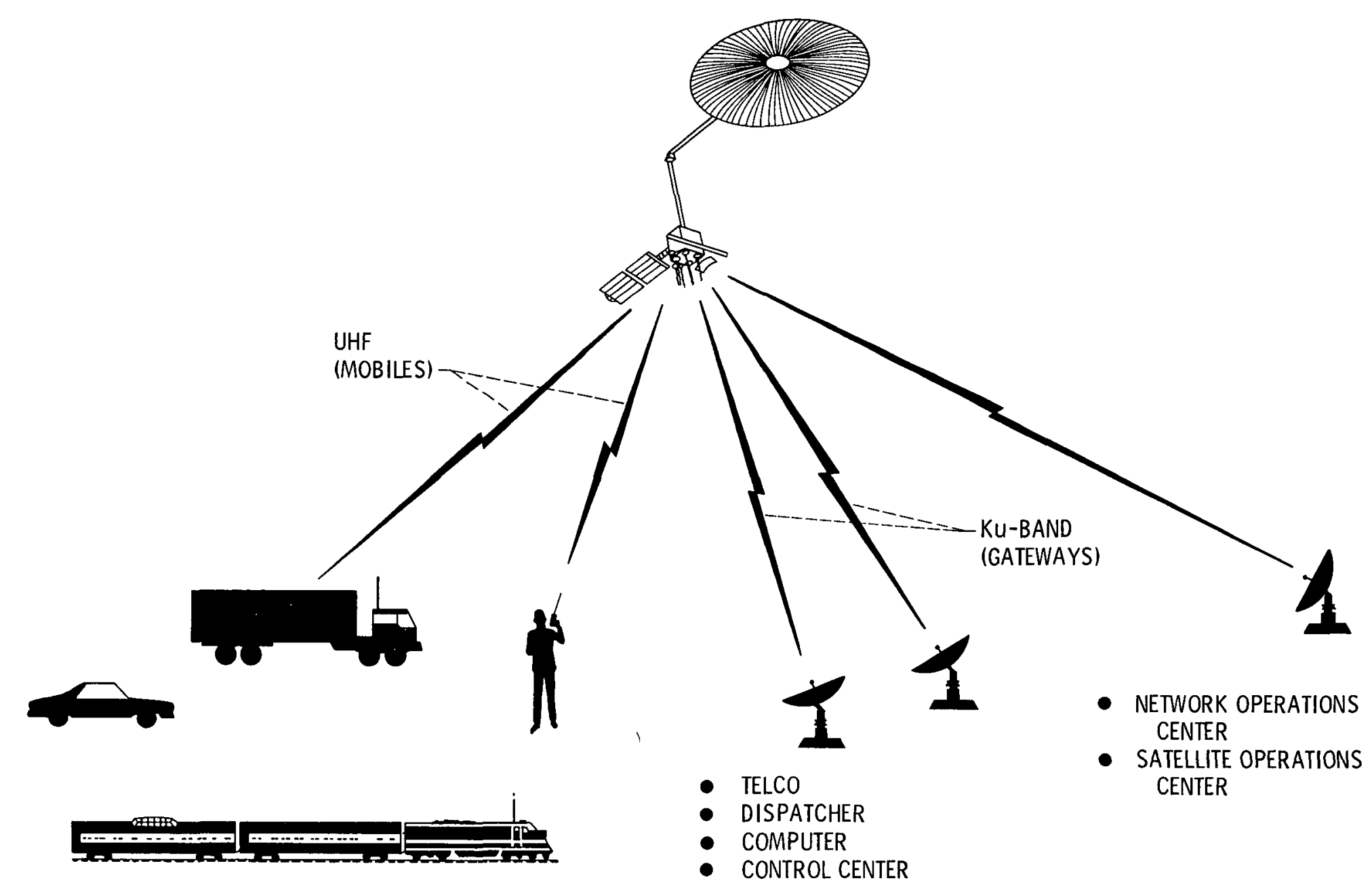

Fig. 3 GE space segment configuration. 


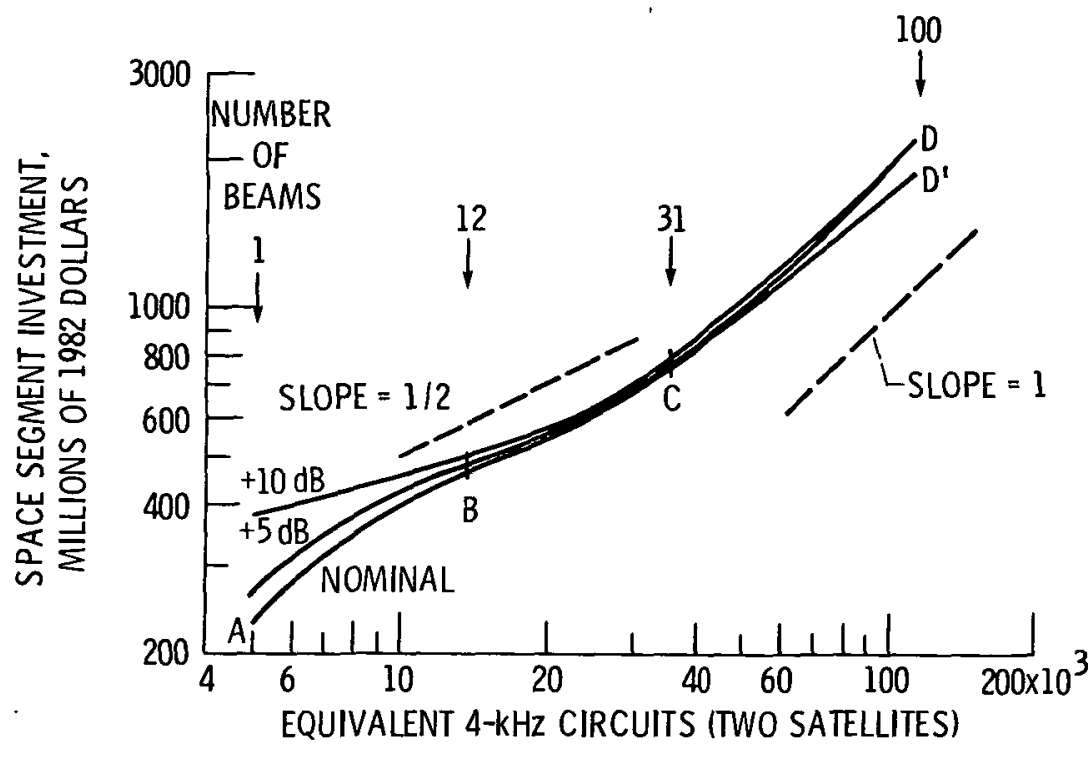

Fig. 4 Space segment investment (capital cost) versus equivalent $4-\mathrm{kHz}$ circuits for various UHF satellite powers. 


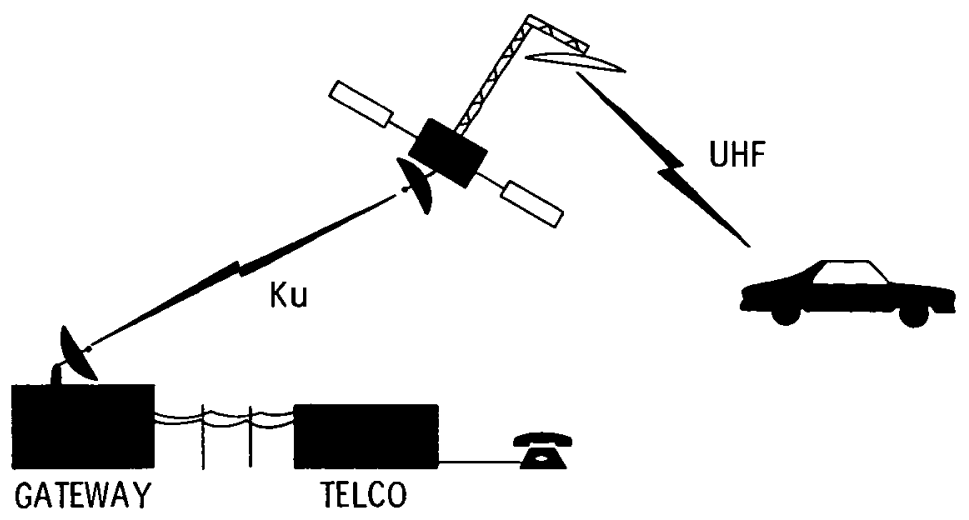

(a) Direct to mobile system.

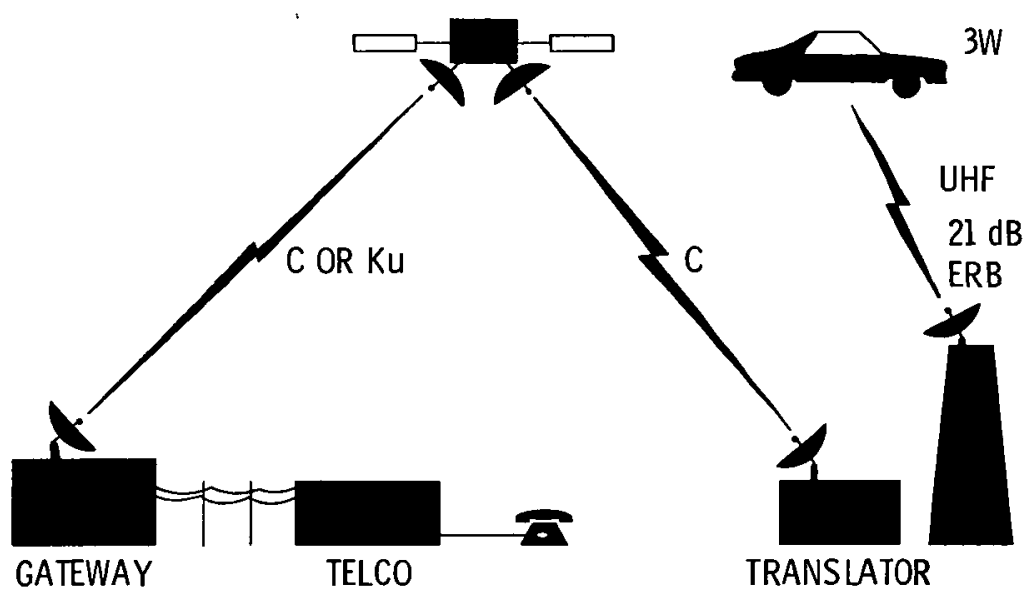

(b) Mobile to translator system.

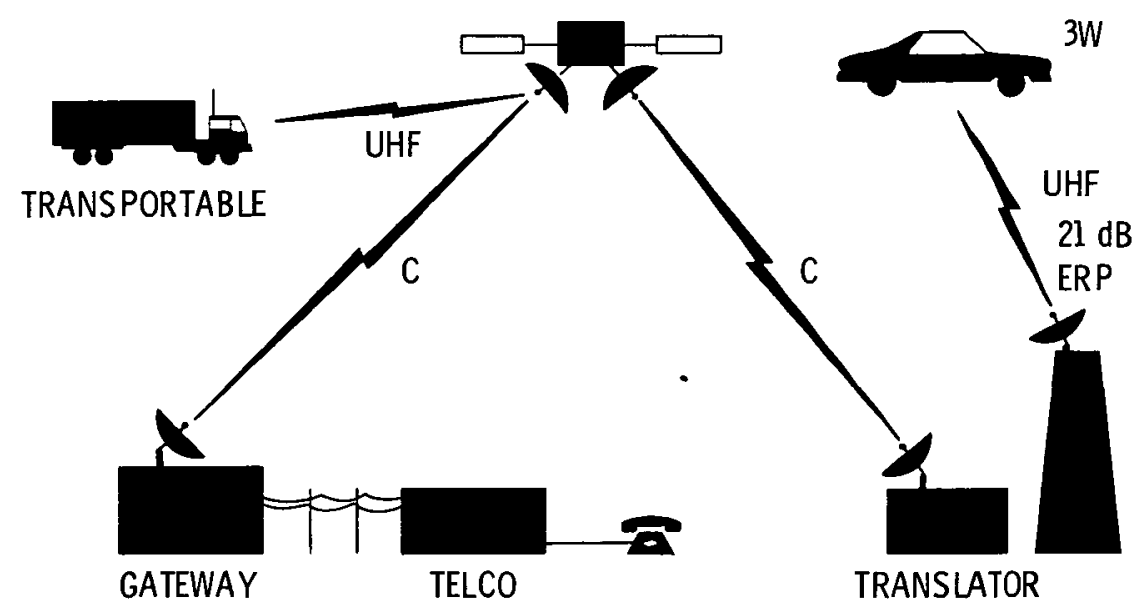

(c) Hybrid system concept.

Fig. 5 TRW mobile radio telephone system configurations. 


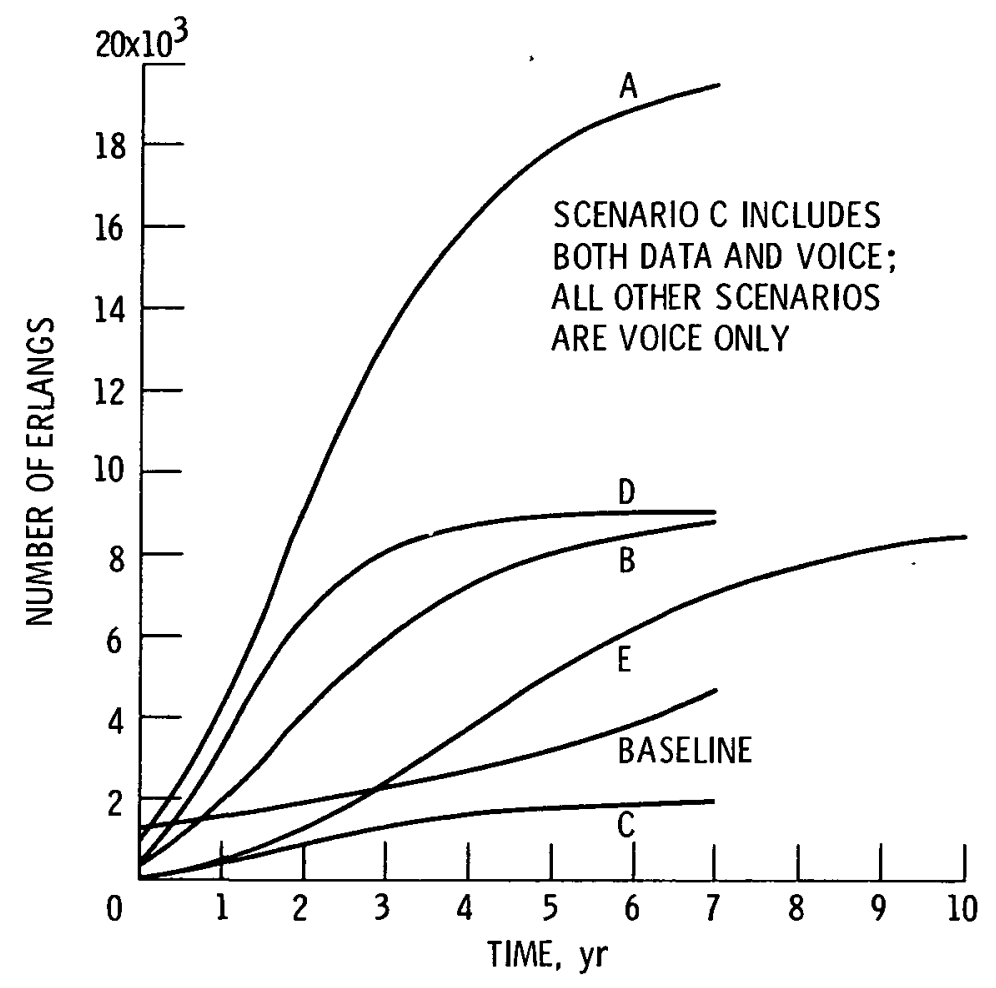

Fig. 6 Traffic scenarios. 


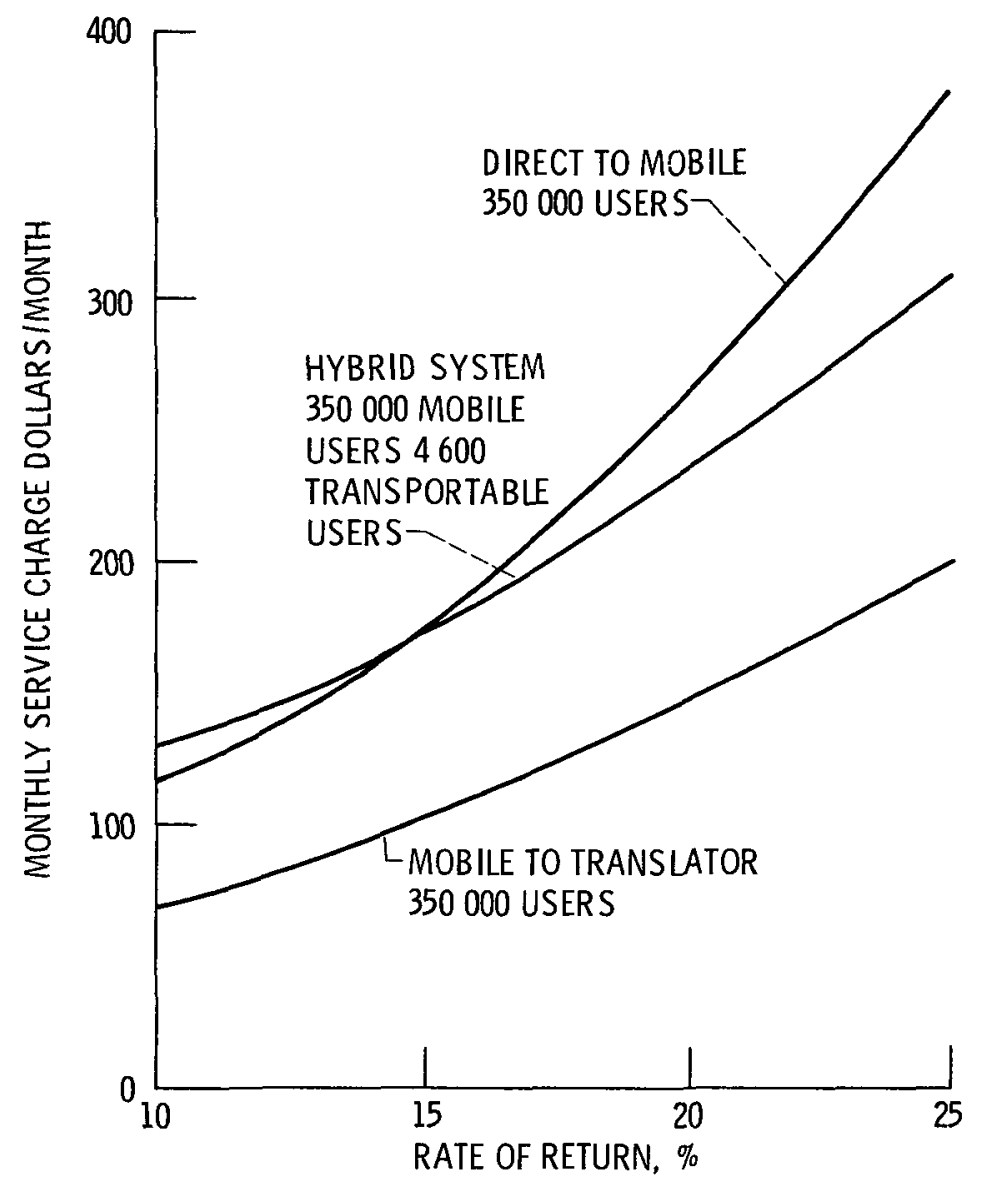

Fig. 7 In the hybrid system, the mobile users and transportable users pay a common service charge.

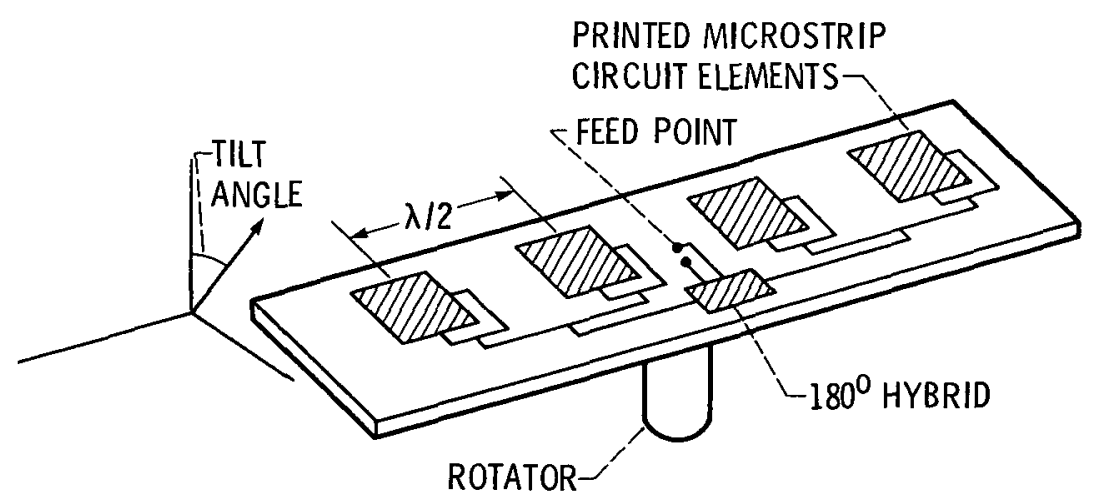

Fig. 8 User antenna concept TRW. 


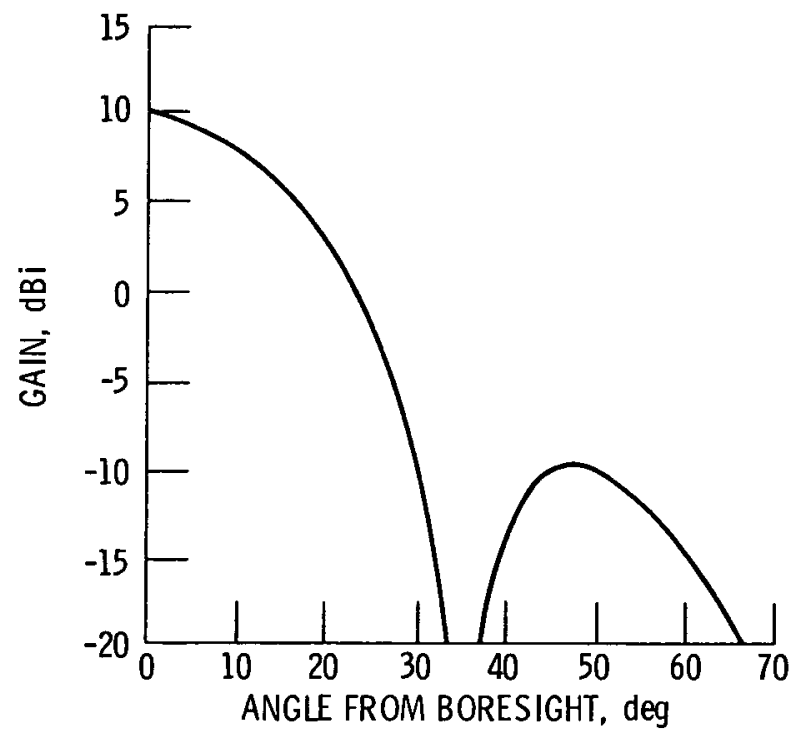

Fig. 9 Azimuthal pattern for 4-element array. 
- SPACE SEGMENT - DEPLOYABLE MULTIBEAM ANTENNA STS ORBIT DEPLOYMENT

- STS UPPER STAGE NEED LAUNCH CAPABILITY GREATER THAN IS CURRENTLY PLANNED

- LINEARIZED UHF AMPLIFIER

- GROUND SEGMENT • GATEWAYS

DEVELOPMENT FOR REDUCING COST

- MOBILE UNITS

MAKE TERRESTRIAL UNITS

SUITABLE FOR SATELLITE SERVICE

- MOBILE UNIT ANTENNA HIGH GAIN AND DIRECTIVITY
- DEPLOYABLE MULTIBEAM ANTENNA STRUCTURAL DEVELOPMENT DYNAMIC MODELING ATTITUDE CONTROL FEED SYSTEM

- STS UPPER STAGE LOW THRUST ORBIT TRANSFER-MINIMIZATION OF RISK

Fig. 10 Comparison of technology requirements.

- MOBILE UNIT ANTENNA

HIGH GAIN AND DIRECTIVITY 


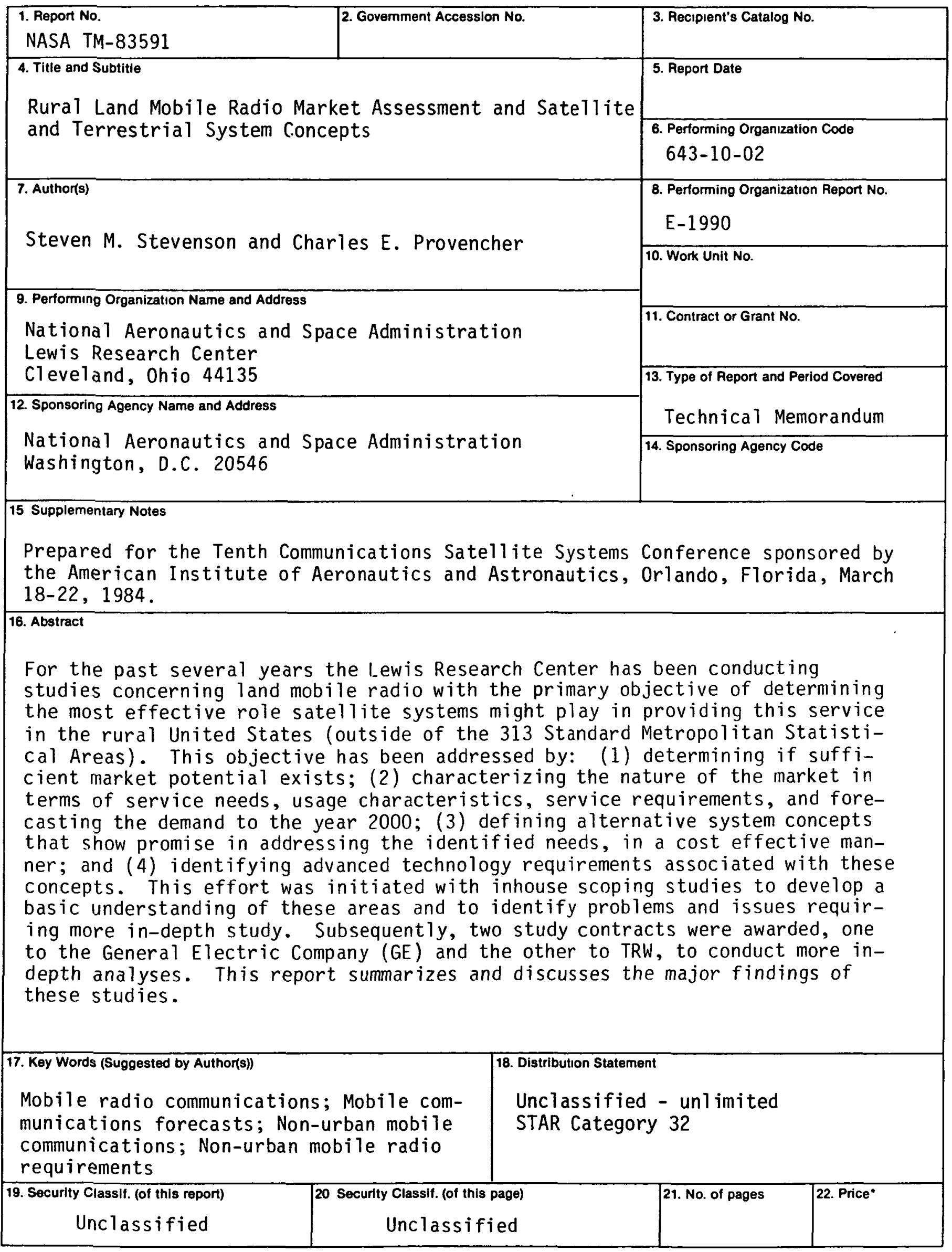

*For sale by the National Technical information Service. Springfield, Virginia 22161 
National Aeronautics and Space Administration

Washington, D.C.

20546

Official Busıness

Penalty for Private Use. $\mathbf{\$ 3 0 0}$
SPECIAL FOURTH CLASS MAIL BOOK

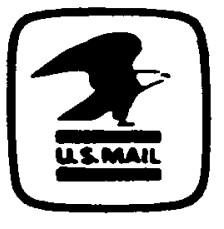

Postage and Fees Pard National Aeronautics and Space Administration NASA 451 